\title{
Theoretical Thermodynamic Study of Crude Extraction by Isentropic Relaxation of Natural Gas
}

\author{
Pierre Jean-Marie R. Dablé*, ${ }^{*}$, Gilles G. Dakoury ${ }^{1}$, Benjamin $\mathrm{Yao}^{2}$, Ado Gossan $^{2}$ and Charles A. \\ Ezouah $^{3}$
}

\author{
${ }^{I}$ Institut National Polytechnique Houphouët BOIGNY de Yamoussoukro, Département de Génie Chimique et \\ Agro-Alimentaire, Laboratoire des Procédés et Mécanique des Matériaux - BP 1093 Yamoussoukro R.C.I. \\ ${ }^{2}$ Institut National Polytechnique Houphouët BOIGNY de Yamoussoukro, Département de Génie Chimique et \\ Agro-Alimentaire, Laboratoire de Procédés Industriels de Synthèse et de l'Environnement - BP 1093 Yamoussoukro \\ R.C.I. \\ ${ }^{3}$ PETROCI-GAZ, Chef du Département Etudes et Développement - BP V 194 Abidjan R.C.I.
}

\begin{abstract}
The process of crude extraction consists of removing the heavy hydrocarbons from natural gas resulting from the layers. The extraction is carried out by the cooling process of the gas phase, to reach the heavy hydrocarbons points of condensation and allow their extraction from the gas phase. This operation is also undertaken using the paraffin oils physicochemical property of heavy molecules absorption.

The study of a process based on the cooling of natural gas carried out by using a turbo expander ensuring isentropic relaxation, appears conclusive. This process converts the energy of relaxation into energy of compression. The cycle of the treatment proposed permits to confer the physical characteristics to the gas which modify its chemical composition returning it by the same time purified from heavy hydrocarbons. This process has the advantage of being definitely less expensive in energy; $22 \mathrm{KwH}$ instead of $427 \mathrm{KwH}$ for crude extraction from the same gas phase by the cooling process.
\end{abstract}

Keywords: Natural gas, crude, heavy hydrocarbons, isentropic, relaxation.

\section{INTRODUCTION}

The natural gas is a mixture of hydrocarbons resulting from the organic material decomposition. It is primarily composed of methane. However, its composition varies from a layer to another. In addition to methane, one finds in natural gas, heavier hydrocarbons such as: ethane, propane, butane and beyond, some condensed gas under the conditions of the layer, but which turn into liquid, when at the surface. The natural gas also contains inter impurities such as carbon dioxide, sulphide of hydrogen, nitrogen as well as water in the state of vapour [1].

To claim under fuel, the natural gas must be dry and not contain any pollutant for the environment. To this end, the natural gas at its exit of the layer undergoes a series of operations, which constitute the natural gas treatment (A. Rojet et al.) [2]. These operations consist of: Relaxation of natural gas for its transport; its dehydration so that the free waters do not cause corrosion of the drains, or blocking of the pressure reducers by the formation of hydrates; the extraction of the acid compounds which are hydrogen sulphide and carbon dioxide; the extraction of crude which consists of the removing of hydrocarbons heavier than methane [3, 4, 5], and finally, the application of a strong-smelling additive by addition of odorous molecules, that are generally mercaptans.

*Address correspondence to this author at the Institut National Polytechnique Houphouët BOIGNY de Yamoussoukro, Département de Génie Chimique et Agro-Alimentaire, Laboratoire des Procédés et Mécanique des Matériaux - BP 1093 Yamoussoukro R.C.I;

E-mail: pjmardable@yahoo.com; dable_pierre@yahoo.fr
The operation of crude extraction presents a notable importance. This allows the control of the dew point of fuel gas. This operation improves in a clear way its calorific value by the way; one thus eliminates the loss of calories which would have been necessary for the evaporation of the easily liquefiable heavy hydrocarbon phases. Lastly, this process allows the production of liquefied petroleum gas (LPG).

The operation of crude extraction is carried out as well by the condensation of heavy hydrocarbons by cooling of the gas phase [6,7], than by the absorption process of these hydrocarbons by paraffin light oils (Wong et al. 2004) [8].

\section{MATERIALS AND METHODOLOGY}

\section{Material}

At the gas station of PETROCI, heavy hydrocarbons extraction from the crude is operated by cooling process of gas phase. This process has an energy cost of $427 \mathrm{KWH}$.

The gas of entry of composition and physical properties present in Tables $\mathbf{1}$ and $\mathbf{1 b i s}$ undergoes a change that leads to a gas of outlet whose composition and physical properties are presented in Tables $\mathbf{2}$ and $\mathbf{2 b i s}$. The composition of the liquid phase (LPG) obtained from the process of separation is presented in Table $\mathbf{3}$.

The application of an isentropic relaxation process studied here, should make it possible to attend the same physical characteristics of the exiting gas from the separator. This 
should then guarantee the same composition of the outlet, so that the crude extraction should have been realised.

Table 1. Composition of the Gas Composition at Entry

\begin{tabular}{|c|c|}
\hline COMPONENT & Molar Fraction \\
\hline \hline Methane & 93.0037 \\
\hline Ethane & 2.7391 \\
\hline Propane & 1.1632 \\
\hline Isobutane & 0.2917 \\
\hline N - Butane & 0.3314 \\
\hline Iso pentane & 0.1266 \\
\hline N - Pentane & 0.1126 \\
\hline N - Hexane & 0.2817 \\
\hline Nitrogen & 1.3436 \\
\hline Carbon dioxide & 0.6152 \\
\hline
\end{tabular}

Table 1bis. Physical Characteristic of Gas of Entry

\begin{tabular}{|c|c|}
\hline Critical temperature $(\mathrm{K})$ & 199.48 \\
\hline Pressure criticises (bars) & 46.39 \\
\hline Hydrocarbon fraction $\mathrm{Y}_{\mathrm{HC}}$ & 0.98044 \\
\hline Factor of compressibility & 0.9482 \\
\hline Temperature & 288 \\
\hline Pressure $(\mathrm{bar})$ & 27.56 \\
\hline Molar flow $(\mathrm{Kmol} / \mathrm{h})$ & 2052.6 \\
\hline Volume throughput $\left(\mathrm{m}^{3} / \mathrm{h}\right)$ & 2058.35 \\
\hline
\end{tabular}

Table 2. Separator Exit Gas Composition

\begin{tabular}{|c|c|}
\hline Compound & Molar Fraction \\
\hline \hline Methane & 93.5415 \\
\hline Ethane & 2.7313 \\
\hline Propane & 1.0794 \\
\hline Iso butane & 0.2580 \\
\hline N-butane & 0.2719 \\
\hline Iso pentane & 0.0751 \\
\hline N-pentane & 0.0527 \\
\hline N-hexane & 0.007 \\
\hline Nitrogen & 1.3525 \\
\hline Carbon dioxide & 0.6142 \\
\hline
\end{tabular}

Table 2bis. Physical Characteristics of Gas at Exit of the Separator

\begin{tabular}{|c|c|}
\hline Critical temperature $(\mathrm{K})$ & 195.72 \\
\hline Critical pressure (bars) & 45.41 \\
\hline Hydrocarbon fraction $\mathrm{Y}_{\mathrm{HC}}$ & 0.9802 \\
\hline Temperature & 240 \\
\hline Pressure & 19 \\
\hline Molar flow $(\mathrm{kmol} / \mathrm{h})$ & 2038.83 \\
\hline Volume throughput $\left(\mathrm{m}^{3} / \mathrm{h}\right)$ & 2051.49 \\
\hline
\end{tabular}

The energetic consideration should then establish, whether the isentropic process using a turbo expander is more beneficial than the cooling process.

Table 3. Composition of the Liquid (LPG) at the Outlet Side of the Separator

\begin{tabular}{|c|c|}
\hline Compound & Liquid Molar Fraction \\
\hline \hline Methane & 14,93 \\
\hline Ethane & 3,93 \\
\hline Propane & 7,86 \\
\hline Iso-butane & 5,45 \\
\hline N-butane & 9,41 \\
\hline Iso pentane & 8,01 \\
\hline N-pentane & 9,27 \\
\hline N-hexane & 40,75 \\
\hline Nitrogen & 0,06 \\
\hline Carbon dioxide & 0,32 \\
\hline
\end{tabular}

\section{THERMODYNAMIC OF THE ISENTROPIC RELAXATION}

In contrary to perfect gases, the real gases change temperature, on great beaches of pressure when they cross points of throttling (valves, isolating valves, diaphragms etc.)

Taking into account the states functions which characterise the gas systems, one distinguishes two types of relaxation known as the isenthalpic relaxation which is carried out with constant enthalpy and the isentropic relaxation with constant entropy.

The Choice of isentropic relaxation is to dispose of sufficient pressure to ensure condensation of liquid phase formed.

From the thermodynamic relations, one establishes that the consequence of the isentropic relaxation on the temperature is independent of the nature of gas. Indeed one has:

The relation of Maxwell:

$(\partial S / \partial P)_{T}=-(\partial V / \partial T)_{P}$

With constant pressure:

$(\partial S / \partial T)_{P}=(C p / T)$

Then the cyclic relation gives:

$(\partial T / \partial P)_{S}=-(\partial S / \partial P)_{T} \times(\partial T / \partial S)_{P}$

The combination of these three relations gives:

$(\partial T / \partial P)_{S}=\left(T \times \alpha_{P} \times V\right) / C_{P}$

With $\alpha_{p}$, the isobar coefficient of compressibility, $\mathrm{T}$ is the temperature of the gas $(\mathrm{K}), \mathrm{V}$ is its molar volume $\left(\mathrm{m}^{3} / \mathrm{mol}\right)$ and $C_{P}$ is its specific heat $(\mathrm{J} / \mathrm{mol} . \mathrm{K})$.

This coefficient that will be noted as $\chi$, and which is the equivalent of the Thomson Joule coefficient for the isenthal- 


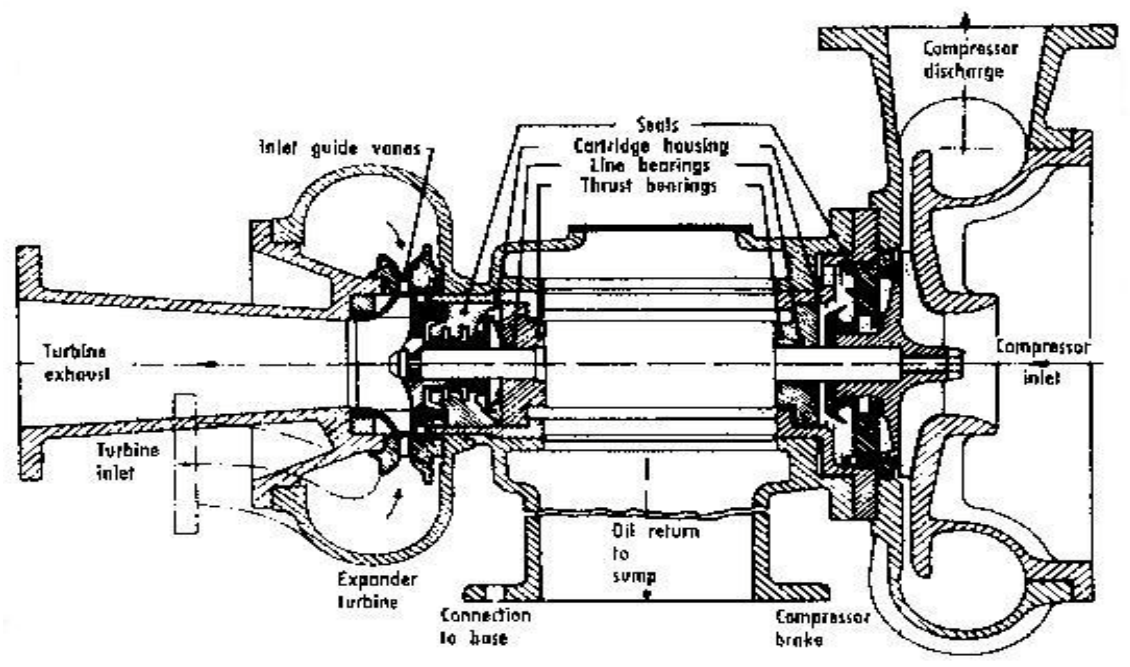

Fig. (1). Longitudinal section of the turbo expander compressor.

pic relaxation, is positive. There is thus a cooling of gas for an isentropic relaxation, whatever may be the nature of the gas.

One carries out this change of state using turbine of relaxation or turbo-expander, Fig. (1). The gas of entry passes by a valve of strangulation, which increases the flow of gas at exit. The molecules are slowed down in contact with a wheel so as to maintain the entropy constant. The wheel, thus put in rotation is coupled to a compressor. The depression undergone by gas in relaxation is thus converted into a recoverable energy.

The advantage of this turbine resides in that the work of relaxation carried out by gas is recovered and used like a source of energy for compression. Like any machine, the turbo compressing pressure reducer is characterised by outputs of operation. For the studied system, we will make the following very realistic assumptions:

Output of the turbine of relaxation: $\mathrm{y}_{\mathrm{T}}=75 \%$

Output in transmission of energy: $\mathrm{y}_{\mathrm{E}}=80 \%$

Output of the turbine of compression: $y_{C}=60 \%$

\section{STATE EQUATION OF REAL GASES}

For a gas, the equation of state is a relation binding the pressure, the temperature and the molar volume of gas. We will choose for our study, model of the gas phase by the REDLICH-KWONG equation of state (Prausnitz et al. 1967) [9] that is valid for pressures lower than 100 bars such as in the present case:

$P=\frac{R \times T}{(V-b)}-\frac{a}{T^{0.5} \times V(V-b)}$

Where $\mathrm{T}$ is the temperature $(\mathrm{K}), \mathrm{b}$ is the co volume of the gas $\left(\mathrm{m}^{3} / \mathrm{mol}\right), \quad R$ is the constant of perfect gases $(8.314 \mathrm{j} / \mathrm{mol} . \mathrm{K})$, a is the parameter of pressure and $\mathrm{V}$ is molar volume $\left(\mathrm{m}^{3} / \mathrm{K} \mathrm{mol}\right)$.
The parameters of this equation of state are calculable from the formulas presented in Table 4.

The parameters of molecular interaction $\mathrm{K}_{\mathrm{ij}}$, which translate the polarity of the molecules will be taken equal to zero, because of the low polarity of the molecules which constitute the studied gas phase.

Table 4. Equation of the Parameter of REDLICH-KWONG

\begin{tabular}{|c|c|}
\hline $\mathrm{a}_{\mathrm{i}}$ & $=0.42748 \cdot \mathrm{R}^{2} \cdot \mathrm{T}^{2.5} / \mathrm{P}_{\mathrm{ci}}$ \\
\hline $\mathrm{a}_{\mathrm{ij}}$ & $=\mathrm{a}_{\mathrm{i} \cdot \mathrm{a}} \cdot \mathrm{a}_{\mathrm{j}}$ \\
\hline $\mathrm{a}$ & $=\sum \sum \mathrm{y}_{\mathrm{i}} \cdot \mathrm{y}_{\mathrm{j}} \cdot \mathrm{a}_{\mathrm{ij}}{ }^{0.5}(1-\mathrm{Kij})$ \\
\hline $\mathrm{b}_{\mathrm{i}}$ & $=0.008664 \cdot \mathrm{R} \cdot \mathrm{T} / \mathrm{P}_{\mathrm{ci}}$ \\
\hline $\mathrm{b}$ & $=\sum \mathrm{y}_{\mathrm{i}} \mathrm{b}_{\mathrm{j}}$ \\
\hline
\end{tabular}

Table 4bis. The REDLICH-KWONG Parameters of the Components Constituting the Gas Phase [13]

\begin{tabular}{|c|c|c|}
\hline Component & ai $\left(\mathrm{Jmol}^{-2} \cdot \mathrm{m}^{-3} \cdot \mathrm{K}\right)$ & bi.10 $\left(\mathrm{m}^{3} \cdot \mathrm{mol}^{-1}\right)$ \\
\hline Methane & 3,217 & 2,969 \\
\hline Ethane & 9,885 & 4,512 \\
\hline Propane & 18,322 & 6,675 \\
\hline Iso-butane & 27,257 & 8,059 \\
\hline N-Butane & 29,011 & 8,066 \\
\hline Iso-pentane & 40,52 & 9,979 \\
\hline N-Pentane & 41,977 & 10,049 \\
\hline Hexane & 56,737 & 12,083 \\
\hline Nitrogen & 1,561 & 2,633 \\
\hline Carbon dioxide & 6,42 & 2,969 \\
\hline
\end{tabular}


The calculation of these parameters taking in accounts the characteristics of the gas and REDLICH-KWONG parameters; Table 4bis, leads to following values presented in Table 4ter.

Table 4ter. Values of the Parameter a and b Calculated

\begin{tabular}{|c|c|c|}
\hline & $\mathbf{a}$ & $\mathbf{b . 1 0}^{\mathbf{5}}$ \\
\hline \hline Loading gas & 3.629 & 3.118 \\
\hline Exiting gas & 3.531 & 3.079 \\
\hline
\end{tabular}

The reduced co-ordinates of temperatures and pressures are calculated from the following equations:

$P_{R}=\left(Y_{H C}\right)^{0.5} \times P / P_{C}$

$T_{R}=T / T_{C}$

From these values, using the abacuses based on the principle of the corresponding states, one determines the characteristics of gas such as the factor of compressibility (Wuithier; 1972a) [10], and the correction of the specific heat (Wuithier; 1972b) [11]. The specific heat of gas is established by the method of the variation versus the idealistic state, thus:

$C_{P}=C_{P}^{*}+\Delta C_{P}$

With:

$C_{P}^{*}=\sum Y_{i} C_{P i}^{*}$

$C_{p i}{ }^{*}$, is the specific heat of component $\mathrm{i}$ at constant pressure according to the temperature, given by expression 10 . The parameters a, b, c and d are being accessible by the table of specific heat of hydrocarbons (Wuithier; 1972c) [12].

$C_{P i}^{*}=a+b T+c T^{2}+d T^{3}$

For the system considered, the specific heat of the loading gas noticed $C_{p l g}^{*}$ and the exiting gas from the separator, $C_{p e g}^{*}$ are given by:

$C_{P \lg }^{*}=19.133+5.9010^{-2} \times T+5.7010^{-6} T^{2}-9.11810^{-9} T^{3}$

$C_{P e g}^{*}=19.249+5.7910^{-2} T+6.8510^{-6} T^{2}-9.44410^{-9} T^{3}$

The $C_{p}$ value is determined by the exploitation of the reduced co-ordinates of gas that give the specific heat $\Delta C_{p}$. The molar volume is given by the following relation (Wuithier; 1972d) [13]:

$V=R \times T\left[1-Y_{H C}\left(1-Z_{H C}\right)\right] / P$

$Y_{H C}$ is the fraction of hydrocarbon in the gas phase considered and $Z_{H C}$ is its given coefficient of compressibility, starting from the pressure and the temperature reduced on the abacus of the factors of compressibility.

The coefficient $\chi$ relating to the isentropic relaxation, gives the ratio of the variation of temperature as compared to that of the pressure. The expression of this coefficient becomes:

$\chi=T(\partial V / \partial T)_{P} / C_{P}$
This coefficient of thermal effectiveness will make it possible to estimate the function of variation:

$T=f(P)$

From the expression of REDLICH-KWONG, one establishes the term $(\partial \mathrm{V} / \partial \mathrm{T})_{\mathrm{p}}$ :

$(\partial V / \partial T)_{P}=\frac{R /\left(V-b+a /\left[2 T^{1.5} \cdot V(V+b)\right]\right)}{R T(V-b)^{2}-a(2 V+b) /\left[T^{0.5} V^{2}(V+b)^{2}\right]}$

The exiting liquid phase is characterized by a molar flow of $13.34 \mathrm{Kmol} / \mathrm{H}$ and a temperature of $240 \mathrm{~K}$.

The study undertaken in this work, consists of the research of the conditions to carry out the extraction of crude from a phase by relaxation, in comparison with this carried out by refrigeration.

The characteristics and physical sizes of gas at the entry and those at exit of the process of refrigeration are known. Thus the processes which will take place during various phases of relaxation will have to make it possible to lead to the same physical conditions and to thus guarantee the same chemical composition of gas at exit, for the same gas phase in entry.

\section{CALCULATION OF THE COEFFICIENTS OF EFFECTIVENESS}

The molar fraction $y_{H C}$ being known, the temperature and the pre reduced pressure are calculated and by treatment of the abacus, the coefficient of compressibility of the gas is given. The molar volume is calculated from expression 11 for the gas pressure at the entry.

The term $(\partial V / \partial T)_{p}$ is given by the relation 14 , and the thermal coefficient of effectiveness is accessible by relation 12. Thus, for a fixed depression, one can calculate the variation in which the temperature of the gas phase undergoes. One thus defines a function power of the form:

$T=K \times P^{X}$

With T the gas temperature at pressure $P, X$ is the power applied and $K$ is a coefficient.

To ensure an optimal operation, the system will have to comprise of various equipments with knowing:

A valve of relaxation carrying out an isenthalpic relaxation to cause a fall of pressure of 7.56 bar; for a weak variation in the temperature of the gas phase; $(\partial \mathrm{T} / \partial \mathrm{P})_{\mathrm{H}}=0.5 \mathrm{~K} / \mathrm{bar}($ Emerson 1990) [14],

A series of exchangers to carry out a pre cooling of the load and to heat residual gas (resulting from the condensation of heavy hydrocarbons from gas of entry). The pressure loss at this level will not have to exceed from 1 bar (Campbell; 1974a) [15]; what would cause a considerable variation of the pressure,

Points of glycol injection to inhibit the formation of hydrates which would come from water contained in the gas phase,

A separator to separate the three phases obtained to know: condensed hydrocarbons, glycol injected and 
purified gas. The process of extraction of crude by isentropic relaxation is schemed at Fig. (2).

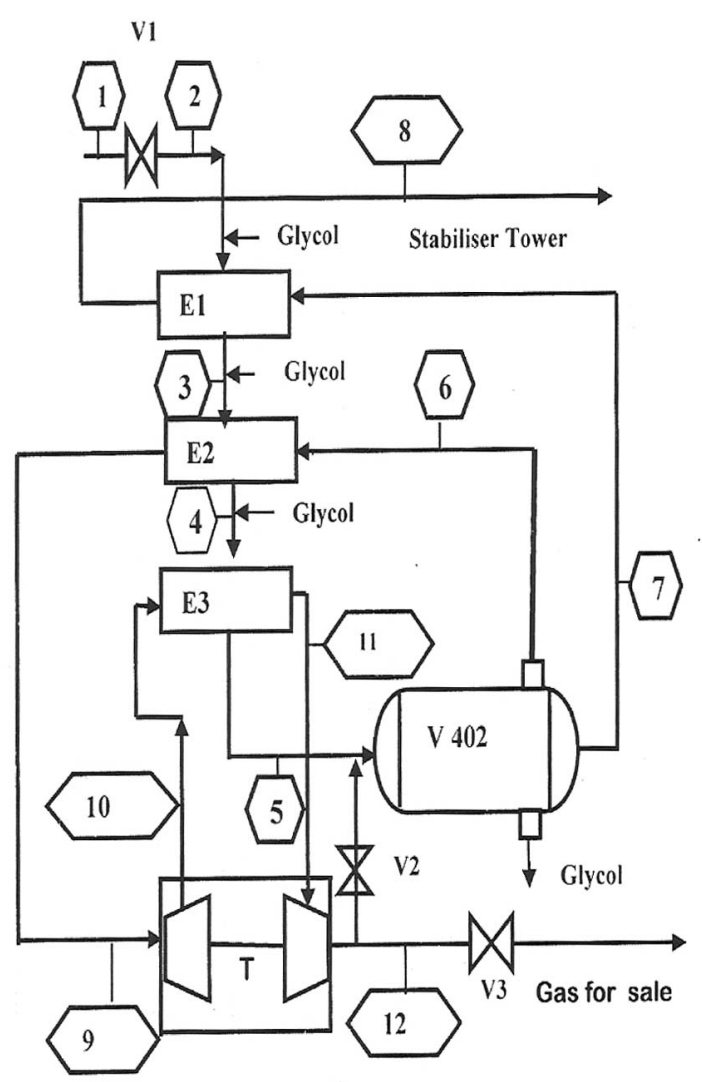

Legend:

$\begin{array}{lll}\mathrm{V} 1 & = & \text { Isenthalpic relief valve } \\ \mathrm{E} 1, \mathrm{E} 2, \mathrm{E} 3 & = & \text { Exchangers } \\ \mathrm{T} & = & \text { Turbo expander compressor } \\ \mathrm{V} 402 & = & \text { Separator } \\ \mathrm{V} 2 & = & \text { Tape admission valve } \\ \mathrm{V} 3 & = & \text { Isenthalpic relief valve }\end{array}$

Fig. (2). Scheme of crud extraction process by isentropic relaxation.

\section{ANALYSIS AND DISCUSSION}

\section{Description of the Isentropic Crude Extraction Process}

\section{Valve 1}

The gas that is received at the station at the pressure of 27.5 bars and $288 \mathrm{~K}$ for temperature will undergoes an isenthalpic relaxation to reach a pressure of 20 bars and a temperature of $284.22 \mathrm{~K}$. This holds of such a relaxation that is carried out with a coefficient of 0.5 . When exiting from the valve, the gas will pass by three exchangers where it will undergo a total depression fixed at 1 bar.

\section{Exchanger E1}

The gas exchanges with the liquid phase of condensation, which is at the temperature of $240 \mathrm{~K}$. The liquid waste must gain $43 \mathrm{~K}$ to observe the conditions of its entry in the tower, where the conditions are fixed at $283 \mathrm{~K}$ and 19 bars of pres- sure. The pressure of gas of load at exit of E1 will be 19.66 bars.

The quantity of heat exchanged in $\mathrm{E} 1$ is given by:

$Q_{1}=C_{P l} \times \Delta T_{l} \times D_{l}$

With $C_{P l}=31.85 \mathrm{Kj} / \mathrm{mol} . \mathrm{K} ; D_{l}=13.34 \mathrm{Kmol} / \mathrm{h} ; \Delta T_{l}=43$ K. That is to say $Q_{l}=18.6210^{3} \mathrm{Kj} / \mathrm{H}$.

The quantity of heat to be exchanged will impose the dimensioning of the exchanger. The temperature of gas of load at exit of E1 is given by:

$\Delta T_{\mathrm{lg}}=Q_{l} /\left(C_{P \mathrm{lg}} \times D_{l}\right)$

With $C_{\mathrm{plg}}$, the calorific capacity of the gas of load.

By making the assumption that $C_{\mathrm{plg}}$ is constant, because of the low flow of the liquid to compare with that of gas:

$D_{\mathrm{lg}}=2038.83 \mathrm{Kmol} / \mathrm{h}$; and $C_{P \mathrm{lg}}=43.42 \mathrm{Kj} / \mathrm{mol} . \mathrm{K}$.

$\Delta T_{\mathrm{lg}}=0.21 \mathrm{~K}$

The variation in temperature is thus negligible. At the exit of E1, the gas of load is at the pressure of 19.65 bars for a temperature equal to $284.22 \mathrm{~K}$.

\section{Exchanger E2}

In this exchanger, the gas of load exchanges with the residual gas from the separator. This residual gas which is with the pressure of 19 bars, must acquire $20 \mathrm{~K}$ to pass from $240 \mathrm{~K}$ to $260 \mathrm{~K}$ and to undergo a depression of 0.35 bars. The quantity of heat to be evacuated by gas of load can be deduced from the expression 17, that is to say $\mathrm{Q}$ is equal to $16.4610^{3} \mathrm{KJ} / \mathrm{h}$.

The outputs of the two gases being very close, the heat gained by the residual gas is equal to that yielded by gas of load, thus loses $20 \mathrm{~K}$ to pass at the temperature of $264.22 \mathrm{~K}$ for a pressure of 19.35 bars at exit of E2.

\section{TURBO RELAXATION}

In the proposed process, the residual gas at exit of the E2 exchanger at the temperature of $260 \mathrm{~K}$ and the pressure of 18.65 bars is carried to turbo-expander to undergo the isentropic relaxation. Therefore, the coefficient of effectiveness is calculated for a depression variation fixed to 1 bar from initial condition of the residual gas, to establish the expression of relation 15 . Table 5 presents the results of these calculations.

Table 5. Theoretical Results

\begin{tabular}{|c|c|c|c|c|c|c|}
\hline $\mathbf{T K})$ & $\mathbf{P}(\mathbf{b a r})$ & $\mathbf{T}_{\mathbf{r}}$ & $\mathbf{P}_{\mathbf{r}}$ & $\mathbf{Z}_{\mathbf{H C}}$ & $\mathbf{C p}$ & $(\partial \mathbf{T} / \partial \mathbf{P})_{\mathbf{S}}$ \\
\hline \hline 260 & 18.65 & 1.33 & 0.395 & 0.955 & 36.32 & -3.05 \\
\hline 256.95 & 17.65 & 1.31 & 0.384 & 0.948 & 38.29 & -3 \\
\hline 253.95 & 16.65 & 1.29 & 0.363 & 0.950 & 36.21 & -3.33 \\
\hline 250.62 & 15.65 & 1.28 & 0.34 & 0.952 & 34.57 & -3.67 \\
\hline 246.95 & 14.65 & 1.26 & 0.32 & 0.950 & 32.34 & -4.11 \\
\hline 242.84 & 13.65 & 1.24 & 0.293 & 0.950 & 29.8 & -4.72 \\
\hline 238.12 & 12.65 & & & & & \\
\hline
\end{tabular}


The graphic function shown in Fig. (3) represents the temperature variation versus pressure during the isentropic relaxation, matches with the following relation:

$T=131.8 \times P^{0.232}$

At exit of the isentropic relaxation, the residual gas will have to be sufficiently cooled so that on the level of the E3 exchanger, the gas of load coming from E2 should leave with the temperature of $240 \mathrm{~K}$, that is to say a fall of temperature of $25 \mathrm{~K}$ and for a pressure of 19 bar conditions to enter the separator.

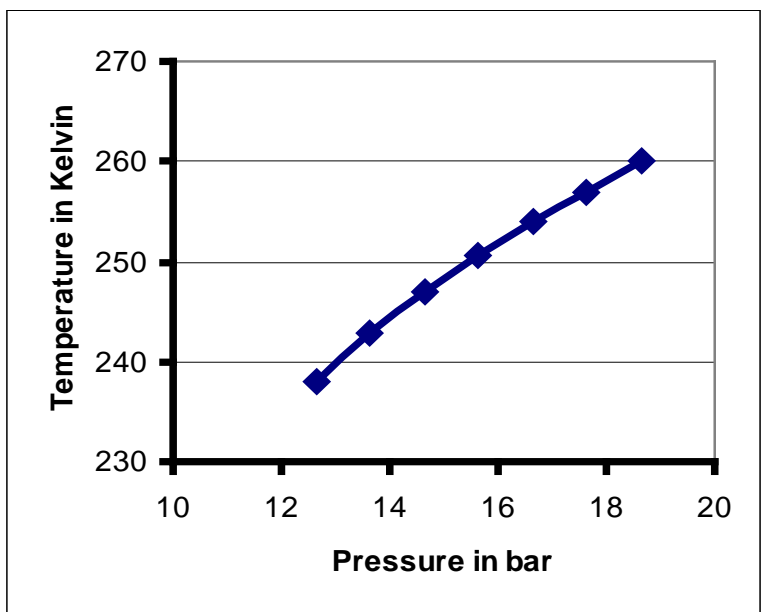

Fig. (3). Temperature variation versus Pressure expressed by relation 17.

To compensate a probable loss of heat, we'll suppose a sufficient fall of temperature of $30 \mathrm{~K}$. By taking into account the output of the pressure reducer, the theoretical variation of the temperature is given by:

$\Delta T_{t h}=\frac{\Delta T_{\text {real }}}{\eta_{t}}$

That is to say $\Delta \mathrm{T}_{\mathrm{th}}=40 \mathrm{~K}$.

The theoretical temperature of residual gas at exit of the isentropic relaxation will be of $220 \mathrm{~K}$. The resolution of expression 18 gives a pressure of 9.11 bars at exit with a real temperature of $230 \mathrm{~K}$. The energy recovered by the wheel is calculated with the following expression:

$W_{r}=D \times\left(H_{e}-H_{s}\right)$

With D, flow of residual gas, $\mathrm{H}_{\mathrm{e}}$ and $\mathrm{H}_{\mathrm{s}}$, are its enthalpies at the entry and the outlet side of the pressure reducer.

For the determination of the enthalpy variation between the two states, one measures the variation versus the idealistic state of these enthalpies. The method consists of making pass gas from a state of entry to an output one, by two isothermal transformations and an isobar, according to the way below:

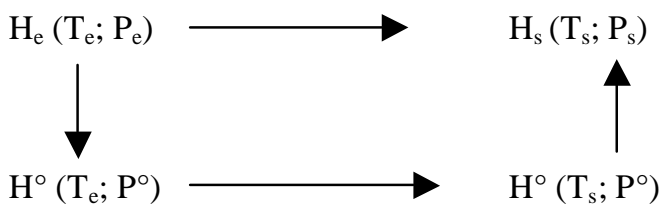

With $\mathrm{H}_{\mathrm{e}}\left(\mathrm{T}_{\mathrm{e}} ; \mathrm{P}_{\mathrm{e}}\right)$, enthalpy of real gas at the entry; $\mathrm{H}^{\circ}\left(\mathrm{T}_{\mathrm{e}}\right.$; $\left.\mathrm{P}^{\circ}\right)$ is the enthalpy of gas considered as perfect at temperature $\mathrm{T}_{\mathrm{e}}$ and $\mathrm{H}^{\circ}\left(\mathrm{T}_{\mathrm{s}} ; \mathrm{P}^{\circ}\right)$ is the enthalpy of gas considered like perfect at the temperature $\mathrm{T}_{\mathrm{S}}$ and $\mathrm{H}_{\mathrm{s}}\left(\mathrm{T}_{\mathrm{S}} ; \mathrm{P}_{\mathrm{S}}\right)$, enthalpy of real gas exiting. The enthalpy variation is given by:

$H_{s}-H_{e}=H^{\circ}\left(T_{e} P^{\circ}\right)-H_{e}\left(T_{e} ; P_{e}\right)+\left[H^{\circ}\left(T_{s} ; P^{\circ}\right)\right.$

$\left.-H^{\circ}\left(T_{e} ; P^{\circ}\right)\right]-\left[H^{\circ}\left(T_{s} ; P^{\circ}\right)-H_{s}\left(T_{s} ; P_{s}\right)\right]$

The enthalpy variation for the isobar transformation is given by:

$\left[H^{\circ}\left(T_{s} ; P^{\circ}\right)-H^{\circ}\left(T_{e} ; P^{\circ}\right)\right]=\int_{T e}^{T s} C p^{*} d t$

The enthalpy accompanying the other transformations which correspond to variations of enthalpy versus the idealistic state, are deduced from the thermodynamic developments. From the first thermodynamic principle and the first CLAPEYRON relation, one has:

$d U=C_{v} \times d T+\left[T(\partial P / \partial T)_{V}-P\right] \times d V$

So, the evolution considered being isothermal and the expression of $d H$ is established as follows:

$d H=\left[T(\partial P / \partial T)_{V}-P\right] \times d V+R \times T \times d Z$

The term $\left[\mathrm{T}(\partial \mathrm{P} / \partial \mathrm{T})_{\mathrm{v}}-\mathrm{P}\right]$ deduced from the equation of REDLICH-KWONG gives:

$\left[T(\partial P / \partial T)_{V}-P\right]=\frac{3 a}{\left[2 \times T^{0.5} \times V(V+b)\right]}$

This lead to:

$d H=\frac{3 a}{2 T^{0.5} \times V(V+b)}+R \times T \times d Z$

The variation of enthalpy versus the idealistic state is given by:

$H-H^{\circ}=R \times T \times\left[(Z-1)+\frac{3 \times a \ln (1+b / V)}{b \times R \times T^{1.5}}\right.$

The variation of enthalpy of gas between its entry and its exit of the turbo pressure reducer is given by:

$\Delta H=-\Delta H_{e}+\int_{T e}^{T s} C p^{*} d T+\Delta H_{s}$

With $\mathrm{H}_{\mathrm{e}}$, the variation versus the idealistic state of gas at the entry and $\mathrm{H}_{\mathrm{s}}$, the exiting gas one. The quantity of heat exchanged is of $1201 \mathrm{~J} / \mathrm{mol}$ corresponding to $1836.5 \mathrm{Kj} / \mathrm{h}$ taking into account the output of 0.75 , for a recovered energy of $510 \mathrm{KwH}$.

\section{Exchanger 3}

The outgoing residual gas from the isentropic relaxation is at the temperature of $230 \mathrm{~K}$ and a pressure 9.11 bars exchanges with the gas from load, which is at the temperature of $264.22 \mathrm{~K}$ and a pressure of 19.33 bars. The loading gas must reach the temperature of $240 \mathrm{~K}$ and a pressure of 19 bars; conditions to enter the separator. The quantity of heat 
that will be exchanged in this exchanger is of $2025 \mathrm{KJ} / \mathrm{h}$. So the residual gas at the exit will be at the temperature of 257 $\mathrm{K}$ for a pressure of 8.78 bars.

\section{TURBO COMPRESSION}

This equipment will have to heat the cold gas from the E3 exchanger by isentropic compression. The objective is to reach conditions for gas of exit, those are $283 \mathrm{~K}$ and 10 bars, the specifications of the gas for sale. For these conditions of entry in the compressor, calculation of the thermal effectiveness coefficient for a suppression fixed at 1 bar leads to an expression of relation 15 that gives:

$T=150 \times P^{0.2455}$

The increase in temperature which the gas will undergo is of $34 \mathrm{~K}$. To compensate the loss of heat, we will estimate at $40 \mathrm{~K}$ the effective profit.

Taking into account the output of the compressor, the theoretical variation of the temperature will be of $24 \mathrm{~K}$. The theoretical temperature of exit of residual thus gas will be of $281 \mathrm{~K}$. The resolution of relation 29 gives a pressure of exit of 12.9 bars. Energy necessary to this compression is accessible by the relation:

$W_{D}=D \times\left(H_{s}^{*}-H_{e}^{*}\right)$

$\mathrm{H}^{*}{ }_{\mathrm{S}}$ is the enthalpy of gas exiting from the compressor, and $\mathrm{H}_{\mathrm{e}}^{*}$ is its enthalpy at the entry. The variation of enthalpy which accompanies this transformation is also established by the measurement of the variations versus the idealistic state. This enthalpy variation calculated gives $939.72 \mathrm{~J} / \mathrm{mol}$; that's $1916 \mathrm{Kj} / \mathrm{h}$, corresponding to $532 \mathrm{KwH}$. The energy available resulting from the conversion of the relaxation one, is provided by the compressor only at $60 \%$; that is to say 1110 $\mathrm{Kj} / \mathrm{h}$. Theoretical energy necessary to ensure the compression of gas is thus of $1343 \mathrm{Kj} / \mathrm{h}$ that is $373.05 \mathrm{KwH}$. For a recovered energy of $510 \mathrm{KwH}$ during relaxation process, the turbo expander compressor must provide $532 \mathrm{KwH}$ to ensure the specification of the gas for sale. So, the cost in energy is of $22 \mathrm{KwH}$.

An energy study carried out on the system of crude extraction form the same natural gas by gas refrigeration, conferring the same physical parameters presents an effective power consumption of 256KwH; (CAMPBELL 1974b) [16]; PETROCI GAZ 2000) [17]. For the same output of 60\%, the theoretical energy necessary for the refrigeration unity to operate would be of $427 \mathrm{KwH}$.

The V2 valve is a tap of admission, which will remain opened until the system stabilises in the conditions of exit of gas fixed by the study, while V3 stays closed. The V3 is an isenthalpic relief valve. As the outlet pressure may be excessive for the installations, 12.9 bars instead of 10 bars, this valve will then ensure a depression of 2.9 bars generating a fall of the temperature of $1.45 \mathrm{~K}$. The gas phase put at the distribution would be then with the pressure of 10 bars and the temperature of $279.55 \mathrm{~K}$ instead of $283 \mathrm{~K}$. So the final gas state will be very closed to the one expected from the refrigeration process characterised by a pressure of $10 \mathrm{bars}$ and a temperature of $283 \mathrm{~K}$.

\section{CONCLUSION}

The process of crude extraction by isentropic relaxation as proposed makes it possible to obtain with balance a gas phase in the physical conditions of 19 bars and $240 \mathrm{~K}$ at the entry of the separator. Under these conditions, the composition of the gas phase is that of the Table 2, which defines the purified gas state.

Point of energetic consideration, the isentropic relaxation has the advantage of being less expensive, since it would require for its operation only $22 \mathrm{KwH}$; the essence of energy necessary being provided by the isentropic relaxation. The quantity of heat exchanged at the level of the exchangers being known, allows the dimensioning of these equipments. Such a system of treatment of natural gas has a greater reliability, since except for the turbo expander, no other system could present dysfunction, and intervenes before the gas phase enter the separator. The possibility of using the isentropic relaxation as crude extraction process remains thus whole and it would be opportune to carry an interest there to the sight of the energy advantages which it presents.

\section{REFERENCES}

[1] WWW.uniongas.com; Chemical composition of Natural gas; consulted Sept. 2008.

[2] A. Rojet, Le Gaz Naturel, Production-Traitement-Transport, Edition Technip 28 Juin 1994.

[3] WWW.freepatentsonline.com; Integrated Heavy Hydrocarbon Removal, Amine treating and Dehydration. United States Patent $\mathrm{N}^{\circ}$ 7396388. Consulted Sept 2008.

[4] WWW.moleculargate.com; Thydrocarbon Dew Point Control and System to meet CARD specification, consulted Sept 2008.

[5] WWW.calgoncarbon.com; Heavy Hydrocarbon Treatment for Gas Processing Applications, consulted Sept 2008.

[6] WWW.freepatentsonline.com; a Cooling and Solidification of Heavy Hydrocarbon Liquid Streams. United State Patent $\mathrm{N}^{\circ}$ 4381986. Consulted Sept 2008.

[7] WWW.freepatentsonline.com; b Process for the recorvery of lisuid Hydrocarbons from a Gaseous Feed Stream an Apparatus for Carrying out this Process. European Patent $N^{\circ}$ EP0395490. Consulted Sept. 2008.

[8] R.C.K. Wong, L.R. Bentley, A.W. Ndegea, A. Chu, M. Gharibi, and S.R.D. Lunn, "Biodegradation of monoethanolamine in soil monitored by electrical conductivity measurement: An observation Approach", Can. Geotech. J., Vol. 41, no. 6; pp. 1026-1037, 2004.

[9] J.M. Prausnitz, and P.L. Chuel, Computer Calculation for High Pressure; Pressure Vapour - Liquid Equilibrium Prentice Hall, Engel Wood Edition, 1967.

[10] P. Wuithier; a. Universal abacus of gases compressibility. Oil Refining and Chemical Engineering (in French). Editions Technip, 1972, p. 84.

[11] P. Wuithier; b. Abacus of the specific heat correction. Oil Refining and Chemical engineering (in French). Editions Technip, 1972, p. 89.

[12] Wuithier P; c. Table of hydrocarbons specific heat parameters at a constant pressure. Oil; Refining and Chemical engineering (in French). Editions Technip, 1972, p. 83.

[13] Wuithier P; d. Oil Refining and Chemical engineering (in French). Editions Technip, 1972, p. 161.

[14] Emerson PROCESS; Poste de détente; rapport de formation, 1990.

[15] John M. Campbell \& Co; Gas processing and conditioning; Equipment Module, $3^{\text {rd }}$ ed.; Harbound; 1974, p. 274. 
[16] John M. Campbell \& Co; Gaz processing and conditioning, Equipment Module, $3^{\text {rd }}$ ed.; Harbound; 1974, p. 93.
Petroci Gaz ; Rapport Unité de dégazolinage (Côte d’Ivoire).

Received: July 02, 2008

@ C Dablé et al.; Licensee Bentham Open

This is an open access article licensed under the terms of the Creative Commons Attribution Non-Commercial License (http://creativecommons.org/licenses/by-nc/3.0/) which permits unrestricted, non-commercial use, distribution and reproduction in any medium, provided the work is properly cited. 